\title{
Credit Risk
}

\section{Jeremy Graveline \\ Assistant Professor of Finance, Carlson School of Management University of Minnesota}

\section{Michael Kokalari \\ Graduate Student, Stanford University}

This review provides a comprehensive survey of recent quantitative research on the pricing of credit risk. It also explores two types of models commonly used for pricing credit risk-structural models and reducedform models. The authors review the contract details and pricing of such popular credit derivatives as credit default swaps, collateralized debt obligations (CDOs), and basket default swaps. They discuss models for correlated default risk and supply an example of pricing a CDO using Monte Carlo analysis.

The global market for credit derivatives has exploded in recent years; the International Swaps and Derivatives Association released a midyear 2006 report giving $\$ 26$ trillion as the notional amount of credit derivatives outstanding. In conjunction with the development of credit derivatives markets, research on credit risk has also increased. The objective of this literature review is to provide an introduction to recent quantitative research on the modeling and pricing of credit risk.

\section{What Are Credit Derivatives?}

Credit derivatives are contracts in which the payout depends on the default behavior of a company or a portfolio of companies. For example:

- A corporate bond portfolio manager may want to protect his portfolio against the extreme event that more than three companies in his portfolio go bankrupt over the next five years. A credit derivatives contract could insure against such a loss in the same way that an out-of-the-money put option could insure an equity portfolio manager against catastrophic losses.

- The credit risk manager at a commercial bank is concerned about her bank's level of exposure to a particular corporate customer, but the lending officer wants to maintain a good relationship with this customer. Credit derivatives would allow the bank to reduce its credit exposure to that one customer with an off-balance-sheet transaction. The equity derivatives analogy is selling a forward contract against one stock in a portfolio, which eliminates the risk but keeps the physical transaction on the books.

- A medium-size commercial bank has concentrated credit risk in a small group of industries (say, manufacturing) but almost no customer exposure and no credit risk exposure to another group of industries (say, consumer products). Credit derivatives allow the bank to reduce its concentrated credit risk and gain exposure to the other sectors.

- A portfolio manager would like to invest in a group of bonds but is restricted from doing so because of the bonds' low credit rating. A credit derivative can repackage the cash flows from these low-rated bonds and offer the portfolio manager an investment with a higher credit rating.

Many dimensions of credit risk affect the prices of credit derivatives and corporate debt. For example, there is the risk that an issuer will default. If an issuer defaults, the payout on its bonds or a related credit derivative is uncertain. Even though an issuer may not default, its credit quality may change, and hence, the price of its bonds can also change. Researchers have proposed quantitative models that address all of these risks. This literature review begins 
with a discussion of models for predicting default. We discuss two types of models commonly used for pricing credit risk: structural models and reduced-form models. We then review the contract details and pricing of such popular credit derivatives as credit default swaps (CDS), collateralized debt obligations (CDOs), 1 and basket default swaps. We conclude with a discussion of models for correlated default risk and an example of pricing a CDO using Monte Carlo analysis.

\section{Predicting Default}

Companies are generally considered to default when they miss a debt payment or file for Chapter 7 or Chapter 11 bankruptcy.2 Altman (1968) developed one of the first quantitative models for predicting bankruptcy. His $Z$-score model formalized the more qualitative analysis of default risk provided by ratings agencies such as Standard and Poor's and Moody's Investors Service. Altman identified five key financial ratios and computed a weighted average of those ratios to arrive at the company's " $Z$-score." Companies with low $Z$-scores are more likely to default than companies with high $Z$-scores. Altman used statistical techniques to determine the best weights to put on each ratio. The most significant financial ratio for predicting default is earnings before income and taxes divided by total assets. The next most significant financial ratio is sales to total assets.

Altman's Z-score model does not incorporate the fact that the characteristics (e.g., financial ratios) of companies change over time. To address this shortcoming, Shumway (2001) estimated a hazard rate model of default. Hazard rate models are widely used in the insurance industry to estimate the probability that an event will happen in a specified period of time-for example, the probability that an auto insurance policy holder will have an accident in the next year, or in the next five years. If $\lambda^{*}$ is the hazard rate for an event (e.g., default), then $1-e^{-\lambda^{*} T}$ is the probability that the event will occur at or before a time $T$ in the future. For small $T, 1-e^{-\lambda^{*} T}$ is approximately equal to $\lambda^{*} T$. That is, the probability that an event such as default will occur over a short time period is approximately the hazard rate for default multiplied by the length of the time period under consideration.

In Shumway (2001), the company's hazard rate (i.e., its probability of default in the next short period) depended on its current financial ratios as well as such market variables as market capitalization, excess equity return, and equity-return volatility. Shumway (2001) found that the inclusion of these market-driven variables improves the predictive ability of hazard rate models. Moreover, he found that the only financial ratios with predictive power are earnings before interest and taxes to total liabilities and market equity to total liabilities.

\section{Structural Pricing Models}

To price a corporate bond or credit derivative, we need to know not only the risk that the company will default but also the compensation that investors demand for bearing that risk. Black and Scholes (1973) and Merton (1974) developed the first models for pricing corporate debt. These models are commonly referred to as structural pricing models because they model the structure of a company's assets and liabilities. Default occurs in the models when the company's assets are not sufficient to meet its liabilities.

A binomial tree example serves to illustrate the intuition behind structural pricing models. Suppose that the risk-free interest rate is 5 percent and that the value of a company's assets is $\$ 120$, but we know that at the end of one year, the company's assets will be worth either $\$ 136$ or $\$ 76$. With these assumptions, we can calculate the current price of a one-year, $\$ 100$ face value zero-coupon bond issued by the company because an investor can replicate the payoff of the company's risky bond by purchasing a combination of the company's assets and a oneyear, zero-coupon risk-free bond.

To determine how much of the company's assets the investor should purchase, we need to examine the payout of the company's risky bond in the two different scenarios. If the company's assets are worth $\$ 136$ next period, then the company will be able to pay the full $\$ 100$ owed to its debtholders, and if its assets are worth $\$ 76$ next

\footnotetext{
1Some market participants consider CDOs to be securities instead of derivatives, but we refer to them as derivatives because their value is derived from the values of their underlying debt instruments.

2Davydenko (2005) addresses the question of whether default is triggered by low asset values or liquidity shortages.
} 
period, then it will only be able to pay $\$ 76$ to its debtholders. ${ }^{3}$ An investor can replicate the payoff on this bond with a portfolio that invests $\$ 48$ in the company's assets and $\$ 43.43$ in a one-period, risk-free, zero-coupon bond. If the company's assets are worth $\$ 136$ next period, then the investor's portfolio will be worth $\$ 100$ because $\$ 48 \times$ $(\$ 136 / \$ 120)+\$ 43.43 \times 1.05=\$ 100$. Similarly, if the company's assets are worth $\$ 76$ next period, then the investor's portfolio will also be worth $\$ 76$ because $\$ 48 \times(\$ 76 / \$ 120)+\$ 43.43 \times 1.05=\$ 76$. If there are no arbitrage opportunities, the price of the corporate bond must, therefore, be equal to the price of the replicating portfolio, $\$ 48+\$ 43.43=\$ 91.43$. Black and Scholes (1973) and Merton (1974) formalized this replication argument in a continuous time setting. Leland (1994) extended the model and allowed the company to optimally choose the time it defaults (which may be before its debt matures).

Structural pricing models can be difficult to implement for companies with complex debt structures, and they have enjoyed relatively little empirical success. For example, Collin-Dufresne, Goldstein, and Martin (2001) found that variation in leverage and volatility account for only a small portion of the variation in a company's credit spread. Nevertheless, Schaefer and Strebulaev (2004) found that structural pricing models are useful for hedging corporate debt with equity.

Structural models also form the basis of Moody's KMV approach to predicting default. In the Black and Scholes (1973) and Merton (1974) pricing models, the assets of the company are lognormally distributed or, equivalently, the logs of the company's assets are normally distributed. Thus, the continuously compounded return on the company's assets is normally distributed. The number of standard deviations between the log of the current value of the company's assets and the log of its liabilities is referred to as the company's distance to default. For example, suppose that the current value of a company's assets is $\$ 100$ and the current value of its liabilities is $\$ 60$. If the volatility of the company's assets is 25 percent, then its distance to default is $(\log 100-\log 60) / 0.25 \approx 2$. KMV maintains a proprietary historical database of the percentage of companies with a given distance to default who defaulted within various time frames. For example, if 0.8 percent of companies with a distance to default of 2 defaulted within one year, then the expected default frequency (EDF) of a company with a distance to default of 2 is 0.8 percent. Interested readers can consult Crosbie and Bohn (2003) and Kealhofer (2003) for more details on KMV's approach to predicting default.

A company's distance to default has also been used in hazard rate models for predicting default. Duffie, Saita, and Wang (forthcoming) develops a hazard rate model that provides estimates of default probabilities over multiple future periods. They model the time series of both company-specific and macroeconomic variables and find that the most influential variable for predicting default is a company's distance to default.

\section{Reduced-Form Pricing Models}

Reduced-form pricing models do not consider the structure of the company's assets and liabilities; instead, they directly model the probability of default (and the payoff in default) using the hazard rate approach. In reducedform pricing models, the company's hazard rate is often referred to as its default intensity. Various flavors of reduced-form pricing models present alternative ways to model the company's default intensity.

Recall that if a company has a default intensity (or, equivalently, a hazard rate) of $\lambda^{*}$, then the probability that it will default at or before a time $T$ in the future is $1-\exp \left(-\lambda^{*} \times T\right)$. For instance, suppose that the default intensity of the company in the example from the previous section is $\lambda^{*}=8.7$ percent; the probability that the company will default within one year is $1-\exp (-0.087 \times 1)=8.33$ percent. If the bond pays $\$ 76$ in the event of default (so that the loss given default is 24 percent of the face value), then the expected payoff on the bond in one year is 91.67 percent $\times \$ 100+8.33$ percent $\times \$ 76=\$ 98$.

\footnotetext{
${ }^{3}$ Note that debtholders are short a put option on the company's assets struck at the face value of the zero-coupon bond. Alternatively, equity can be viewed as a call option on the assets of the company struck at the face value of the zero-coupon bond.
} 
To compute the current value of the zero-coupon bond, we must find the present value of the expected bond payoff in one year. In financial analysis, we typically discount future cash flows using a discount rate that is composed of the risk-free rate plus an adjustment for risk (often computed using the capital asset pricing model or a similar model). To price corporate bonds and credit derivatives, rather than adjust the discount rate to account for risk, we adjust the default probabilities (or equivalently, the default intensities) to account for risk. These riskadjusted default intensities are known as risk-neutral default intensities (equivalently, risk-neutral default probabilities). ${ }^{4}$ If we compute the expected payoff on the bond in one year using the risk-neutral default intensity (which contains an adjustment for risk), then we can use the risk-free discount rate (rather than a risk-adjusted discount rate) to compute the present value of the bond. 5

To illustrate the use of risk-neutral default intensities for pricing, suppose that the company in the previous example has a risk-neutral default intensity of 18.23 percent. Its risk-neutral probability of default within one year is $1-\exp (-0.1823 \times 1)=16.66$ percent, and the risk-neutral discounted expected payoff on the bond is $(83.34$ percent $\times 100+16.66$ percent $\times \$ 76) / 1.05=\$ 91.43$. It is important to remember that the risk-neutral default intensity that is used to price a company's risky debt is not the same as the company's actual default intensity. A company's risk-neutral intensity contains an adjustment for risk, and thus it is typically higher than its actual intensity in order to incorporate investors' aversion to bearing the risk of default. Intuitively, reduced-form pricing models use risk-neutral probabilities to essentially pretend that the probability of an undesirable event (such as default) is actually higher than the true probability.

If we analyze the difference between the actual default intensity and the risk-neutral default intensity, we arrive at an indicator of how much compensation investors require to bear default risk. If this difference is large, then investors demand a large premium for bearing credit risk and credit spreads are wide. In the previous example, the company's risk-neutral default intensity was 2.1 times higher than its actual default intensity (18.23 percent/ 8.7 percent $=2.1$ ). Driessen (2005) and Berndt, Douglas, Duffie, Ferguson, and Schranz (2005) found that this ratio varies through time and its average value is about 2 for most companies. Elton, Gruber, Agrawal, and Mann (2001) also provided empirical evidence for the existence of a risk premium on corporate debt.

Note that if the price of the one-period zero-coupon bond is $\$ 91.43$, then the yield on the bond is 9.373 percent, so the credit spread is 4.373 percent above the 5 percent risk-free rate. The credit spread can be approximated as the product of the risk-neutral default intensity, 18.23 percent, and the loss given default, 100 percent -76 percent $=24$ percent, which is $0.1823 \times 0.24=4.375$ percent. Intuitively, this approximation works because the credit spread is determined by the rate of default (the default intensity) multiplied by the amount that is lost in the event of default. This relationship can, in turn, be used as a back-of-the-envelope calculation to reverse engineer a company's risk-neutral default intensity given its credit spread and an assumption about the percentage of value lost in the event of default. For example, if a company's credit spread is 7.2 percent and we assume that the percentage lost in the event of default is 60 percent, then its risk-neutral default intensity is roughly $0.072 / 0.60=12$ percent .

In the category of reduced-form pricing models, Jarrow, Lando, and Turnbull (1997), Lando (1998), and Duffie and Singleton (1999b) provided popular models for risk-neutral default intensities and recovery rates. Duffie, Pedersen, and Singleton (2003) applied the model in Duffie and Singleton (1999b) to the pricing of sovereign debt. Duffee (1999) found that a reduced-form pricing model is reasonably successful at pricing the debt of 161 different companies. The models in all of these studies allow a company's risk-neutral default intensity to vary stochastically through time to reflect changes in the company's credit quality and/or the market's aversion to bearing credit risk.

\footnotetext{
${ }^{4}$ The term "risk neutral" comes from the idea that a risk-neutral investor is an investor that does not require a higher expected investment return in exchange for investing in riskier securities and, therefore, the investor discounts all cash flows at the same risk-free rate. Obviously, such an investor does not really exist, but if we use risk-neutral default intensities, then we can present value payoffs using the risk-free discount rate as if we were a risk-neutral investor.

5In theory, the same risk-neutral default intensity can be used to value all of the company's corporate debt and any credit derivatives with payoffs that may depend on whether the company defaults. By contrast, each of these securities may require a different risk-adjusted discount rate for valuation. This convenience is one reason why risk-neutral default intensities have become the industry standard for pricing.
} 
In practice, the recovery or loss given default is also uncertain. Altman, Brady, Resti, and Sironi (2005) and Acharya, Bharath, and Srinivasan (forthcoming 2006) find that recovery rates on corporate defaults tend to go down during economic downturns when the number of defaults increases. However, most reduced-form pricing models make the simplifying assumption that investors recover a fixed fraction of face value or market value in the event of default. For example, a typical assumption is that investors recover 40 percent of the value of the bond just prior to default.

\section{CDS}

Now that we have introduced the models that are used to price credit risk, we can begin to examine the pricing of credit derivatives. One of the most popular credit derivatives is a credit default swap, or CDS, which serves as insurance against default by a company. The buyer of this insurance pays an annuity premium until maturity of the swap or default by the company, whichever event occurs first. In return for this annuity premium, in the event that the company defaults, the buyer of this default insurance receives the difference between the face value and the market value of a specified bond that the company has defaulted on. There are many variations on the standard default swap, but this discussion will focus on this basic version. As with the vast majority of credit derivatives, CDS are traded in the over-the-counter market (rather than on a financial exchange), and the terms are typically standardized by the International Swaps and Derivatives Association. Each counterparty is exposed to the risk that the other will default. 6 To mitigate this risk, over-the-counter derivatives typically include netting and collateral agreements, and most financial institutions limit their aggregate potential exposure to each counterparty.

When there is no default by the underlying issuer, the buyer of protection makes periodic swap payments, $S$, until the swap matures at time $T$. The seller of protection is not obligated to make any payments because the underlying issuer does not default. When the underlying issuer does default (say, at time $\tau$ ), the CDS terminates and the seller of protection is obligated to make an insurance payment, $I$, which is usually required to be the difference between the face value and the market value (after default) of a specific bond that the company has defaulted on.

Duffie (1999) showed that the at-market default swap rate (or the insurance annuity premium) for a company is approximately equal to the credit spread on a par floating rate note issued by the company with the same maturity as the default swap. ${ }^{7}$ This pricing relationship exists because one can replicate a short position in a default swap with a portfolio that is long the company's par floating rate note and short a risk-free par floating rate note (or, alternatively, the portfolio borrows at the risk-free floating rate). In periods when the company does not default, the cash flow from the portfolio is equal to the credit spread, which is the difference between the coupon payments on the risky par floating rate note and the risk-free par floating rate note. If the company does default, the portfolio receives the recovery value of the company's bond and pays the par value of the risk-free loan. Because the initial value of the portfolio is $\$ 0$ and it pays the same amount as a short position in the default swap in the event of default, the default swap rate must be equal to the credit spread. Duffie (1999) illustrated how one can approximate a company's default swap rate in situations in which the company does not have a par floating rate note with the same maturity as the default swap.

A default swap can also be valued using the risk-free yield curve and the company's risk-neutral default intensity. Assume that the company's risk-neutral default intensity is $\lambda$ and the default swap payments are $S$ at times $T_{1}, \ldots, T_{N}$. A payment of $S$ is due at time $T_{n}$ if the company has not defaulted by that time. The riskneutral probability that the company does not default by $T_{n}$ is $\exp \left(-\lambda T_{n}\right)$. If $R$ is the continuously compounded yield on a risk-free zero-coupon bond that matures at time $T_{n}$, then the present value $P_{n}$ of the swap payment is

\footnotetext{
${ }^{6}$ Duffie and Huang (1996) provided a model for valuing over-the-counter derivatives where both counterparties in the contract can default. 7The at-market default swap rate is the required annuity premium so that the value of the swap is zero for both counterparties.
} 


$$
P_{n}=\underbrace{e^{-R T_{n}}}_{\text {Risk-free discount }} \times \underbrace{e^{-\lambda T_{n}}}_{\begin{array}{c}
\text { Risk-neutral } \\
\text { probability } \\
\text { that } \\
\text { payment is required }
\end{array}} \times \underbrace{S}_{\text {Swap payment }}=e^{-(R+\lambda) T_{n}} S .
$$

Therefore, the present value of all the insurance premium payments is

$$
\sum_{n=1}^{N} P_{n}=S \sum_{n=1}^{N} e^{-(R+\lambda) T_{n}}
$$

To value the other side of the swap, assume that the buyer of default protection receives a payment $I$ at time $T_{n}$ if the company defaults between time $T_{n-1}$ and time $T_{n}$. The risk-neutral probability that the company will default between $T_{n-1}$ and $T_{n}$ is

$$
\underbrace{\left(1-e^{-\lambda T_{n}}\right)}_{\begin{array}{l}
\text { Risk-neutral } \\
\text { probability of } \\
\text { default by } T_{n}
\end{array}}-\underbrace{\left(1-e^{-\lambda T_{n-1}}\right)}_{\begin{array}{l}
\text { Risk-neutral } \\
\text { probability of } \\
\text { default by } T_{n-1}
\end{array}}=e^{-\lambda T_{n-1}}-e^{-\lambda T_{n}} .
$$

Therefore, the value of all of the possible insurance payments is

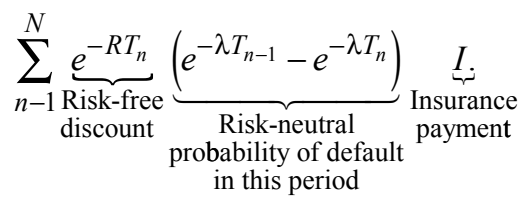

Finally, the value of the default swap is the value of the payments received minus the value of the payments made,

$$
I \sum_{n=1}^{N} e^{-R T_{n}}\left(e^{-\lambda T_{n-1}}-e^{-\lambda T_{n}}\right)-S \sum_{n=1}^{N} e^{-(R+\lambda) T_{n}} .
$$

At inception of a default swap, the at-market swap rate $S^{*}$ is chosen so that the value of the default swap is zero,

$$
S^{*}=\frac{I \sum_{n=1}^{N} e^{-R T_{n}}\left(e^{\left.-\lambda T_{n-1}-e^{-\lambda T_{n}}\right)}\right.}{\sum_{n=1}^{N} e^{-(R+\lambda) T_{n}}} .
$$

For example, suppose that a company's risk-neutral default intensity is 0.03 , and in the event that the company defaults, we expect that its bonds will lose 40 percent of their face value. The payments on a semiannual swap are at times $0.5,1,1.5, \ldots, 4.5,5$. We can write this more formally as $n \times 0.5$ for $n=1, \ldots, 10$. If the continuously compounded interest rate is 6 percent, then the semiannual swap payments on a five-year CDS are

$$
S^{*}=\frac{0.4 \sum_{n=1}^{10} e^{-0.06(n \times 0.5)}\left[e^{-0.03(n-1) \times 0.5}-e^{-0.03(n \times 0.5)}\right]}{\sum_{n=1}^{10} e^{-(0.06+0.03)(n \times 0.05)}}=0.6 \text { percent. }
$$

The semiannual swap rate would typically be quoted on an annual basis as $2 \times 0.6$ percent $=1.2$ percent. If the notional amount on the swap was $\$ 1$ million, then the buyer of protection would make semiannual payments of 0.6 percent $\times \$ 1$ million= $\$ 6,000$ and would receive 40 percent $\times \$ 1$ million $=\$ 400,000$ in the event of default (assuming that the company's bonds lose 40 percent of their face value in the event of default). 


\section{Time-Varying Default Intensities}

In many reduced-form pricing models, a company's risk-neutral default intensity varies either deterministically or randomly (stochastically) through time. In other words, the company's risk-neutral default intensity is a function of time. For example, the company's risk-neutral default intensity in the first year is $\lambda(1)$, and in the second year it is $\lambda(2)$. Because we are allowing $\lambda$ to vary over time, we use the notation $\lambda\left(T_{i}\right)$ to denote a company's riskneutral default intensity between time $T_{i-1}$ and time $T_{i}$. With this notation, the risk-neutral probability that the company will not default by time $T_{n}$ is the product of the conditional probabilities that it will not default during each individual period,

$$
\begin{aligned}
e^{-\lambda\left(T_{1}\right) T_{1}} e^{-\lambda\left(T_{2}\right)\left(T_{2}-T_{1}\right)} \ldots e^{-\lambda\left(T_{n}\right)\left(T_{n}-T_{n-1}\right)} & =e^{-\sum_{i=1}^{n} \lambda\left(T_{i}\right)\left(T_{i}-T_{i-1}\right)} \\
& =e^{-\Lambda\left(T_{n}\right) T_{n}},
\end{aligned}
$$

where 8

$$
\Lambda\left(T_{n}\right)=\sum_{i=1}^{n} \lambda\left(T_{i}\right) \times \frac{\left(T_{i}-T_{i-1}\right)}{T_{n}}
$$

and

$$
T_{0}=0 .
$$

With this extension, the value of a default swap that matures at time $T_{N}$ is

$$
I \sum_{n=1}^{N} e^{-R T_{n}}\left[e^{-\Lambda\left(T_{n-1}\right) T_{n-1}}-e^{-\Lambda\left(T_{n}\right) T_{n}}\right]-S \sum_{n=1}^{N} e^{-\left[R+\Lambda\left(T_{n}\right)\right] T_{n}} .
$$

Similarly, the default swap rate $S^{*}$ at the inception of an at-market default swap is 9

$$
S^{*}=\frac{I \sum_{n=1}^{N} e^{-R T_{n}}\left[e^{-\Lambda\left(T_{n-1}\right) T_{n-1}}-e^{-\Lambda\left(T_{n}\right) T_{n}}\right]}{\sum_{n=1}^{N} e^{-\left[R+\Lambda\left(T_{n}\right)\right] T_{n}}} .
$$

This pricing relationship is often used to reverse engineer (or bootstrap) the term structure of the company's risk-neutral default intensity for each period from the term structure of its default swap rates. This bootstrapping procedure is very similar to the procedure that is used to infer the zero-coupon yield curve from the yields on bonds with different maturities. See Duffie (1999) for more details. Hull and White (2000), Hull and White (2001), and O'Kane and Turnbull (2003) are other excellent resources for pricing CDS.

\section{Simulating Default Times}

When interest rates and default intensities vary through time (and, therefore, are not constant), computing default probabilities and prices in closed form can be difficult. In these situations, it is convenient to use Monte Carlo simulations for computations. 10 Monte Carlo analysis requires that one be able to simulate a random default time $\tau$ from a given time-varying intensity $\lambda(\cdot) .{ }^{11}$ The following algorithm can be used for these simulations:

1. Simulate a random number $U$ that is uniformly distributed between 0 and 1 .

8Note that in the special case that the default intensity is constant [i.e., $\lambda\left(T_{i}\right)=\lambda$ for all $i$ ], we have $\Lambda\left(T_{n}\right)=\sum_{i=1}^{n} \lambda\left(T_{i}\right) \frac{\left(T_{i}-T_{i-1}\right)}{T_{n}}=\lambda$.

${ }^{9}$ This formula assumes that interest rates are constant across maturities. Interest rates often differ, however, with the time to maturity (i.e., the yield curve does not have to be flat). To incorporate this possibility, we can replace $R T_{n}$ in this formula with $R\left(T_{n}\right) T_{n}$, where we have used the notation $R\left(T_{n}\right)$ to denote the continuously compounded yield on a zero-coupon bond that matures at time $T_{n}$.

${ }^{10}$ The last section in this literature review provides a more detailed example of pricing a credit derivative using Monte Carlo analysis.

$11 \mathrm{We}$ use the notation $\lambda(\cdot)$ to indicate that the company's risk-neutral default intensity can be a function of time (and, therefore, it does not need to be constant). 
2. Set the default time $\tau$ depending on what the value of the random number $U$ is in the previous step.

- Set $\tau=T_{1}$ if

$$
0<U \leq 1-e^{-\Lambda\left(T_{1}\right) T_{1}} .
$$

- Set $\tau=T_{2}$ if

$$
1-e^{-\Lambda\left(T_{1}\right) T_{1}}<U \leq 1-e^{-\Lambda\left(T_{2}\right) T_{2}} .
$$

- In general, set $\tau=T_{m}$ if 12

$$
1-e^{-\Lambda\left(T_{m-1}\right) T_{m-1}}<U \leq 1-e^{-\Lambda\left(T_{m}\right) T_{m}} .
$$

Figure 1 illustrates this procedure for choosing the correct default time $\tau$ that corresponds to each interval for the uniform random number $U$.

Duffie and Singleton (1999a) is a good resource on simulating default times.

Figure 1. Simulating Default Times from Uniform Random Numbers

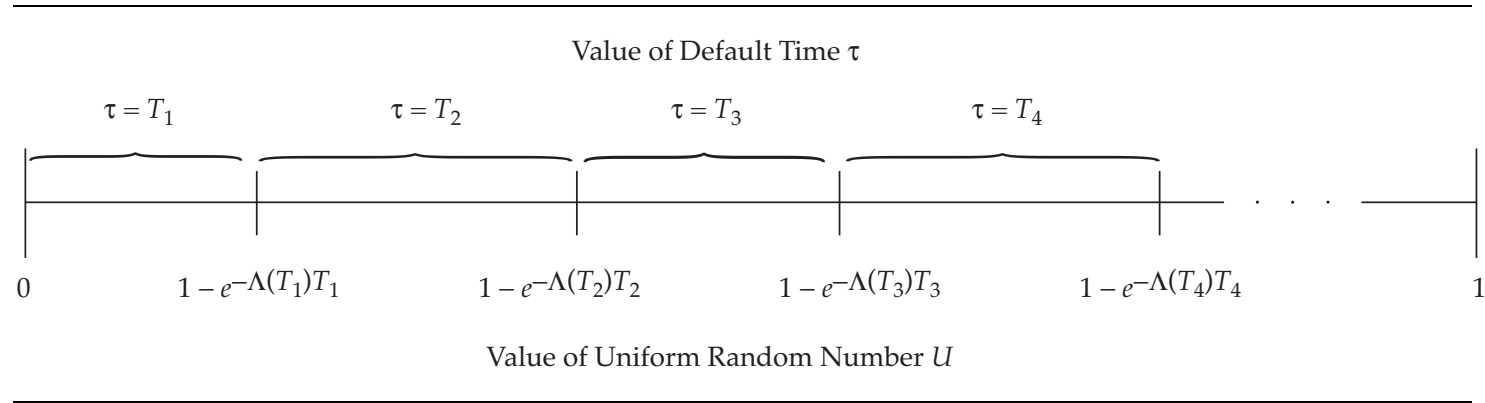

\section{Example of Simulating Default Times}

To illustrate this simulation procedure, consider the following example. Suppose that we are interested in three periods: $T_{1}=1, T_{2}=2$, and $T_{3}=3$. The company has a default intensity of $\lambda(1)=10$ percent during the first year, $\lambda(2)=14$ percent during the second year, and $\lambda(3)=8$ percent during the third year. We would like to simulate a default time $\tau$ for the company such that $\tau=1$ if the company defaults in the first year, $\tau=2$ if the company defaults in the second year, and $\tau=3$ if the company defaults in the third year.

1. First, generate a random number $U$ that is uniformly distributed between 0 and 1 [in Microsoft Excel, use the function $\operatorname{RAND}(\cdot)]$.

2. Next, compute the following values:

$$
\begin{array}{r}
\Lambda\left(T_{1}\right) \times T_{1}=0.1 \times 1 \Rightarrow 1-e^{-\Lambda\left(T_{1}\right) T_{1}}=0.095 \\
\Lambda\left(T_{2}\right) \times T_{2}=0.1 \times 1+0.14 \times 1 \Rightarrow 1-e^{-\Lambda\left(T_{2}\right) T_{2}}=0.213 \\
\Lambda\left(T_{3}\right) \times T_{3}=0.1 \times 1+0.14 \times 1+0.08 \times 1 \Rightarrow 1-e^{-\Lambda\left(T_{3}\right) T_{3}}=0.274 .
\end{array}
$$

3. Finally, assign $\tau$ according to the following values of $U$ :

$$
\begin{aligned}
0 \leq U \leq 0.095 & \Rightarrow \tau=1 \\
0.095<U \leq 0.213 & \Rightarrow \tau=2 \\
0.213<U \leq 0.274 & \Rightarrow \tau=3 .
\end{aligned}
$$

If $0.274<\mathrm{U} \leq 1$, then the company does not default during the first three periods.

${ }^{12}$ Recall that $\Lambda\left(T_{m}\right)\left(T_{m}\right)=\sum_{i=1}^{m} \lambda\left(T_{i}\right)\left(T_{i}-T_{i-1}\right)$. 
Intuitively, one can see that the algorithm works because the size of the interval for $U$ that corresponds to each value of $\tau$ is exactly the probability of default during that period. For example, the size of the interval for $U$ that corresponds to $\tau=2$ is

$$
0.213-0.095=e^{-\Lambda\left(T_{1}\right) T_{1}}-e^{-\Lambda\left(T_{2}\right) T_{2}} .
$$

\section{CDOs}

Collateralized debt obligations, or CDOs, are another popular class of credit derivatives. A CDO tranches out the default risk in an underlying portfolio of bonds or loans to junior and senior investors.

To illustrate the concept of tranching, consider a portfolio of 10 bonds, each of which has a face value of $\$ 100$ (the total face value of the portfolio is $\$ 1,000$ ). An investor in a mutual fund containing 10 bonds shares the default losses in proportion to his or her ownership of the fund. In a CDO containing 10 bonds, however, the default risk exposure is allocated differently. If a CDO is tranched into a senior tranche of 80 percent and a junior tranche of the remaining 20 percent, then investors in the junior tranche own the first loss piece or equity tranche and they suffer all losses up to 20 percent (or $\$ 200$ in face value of the bonds). An investment in the junior tranche is typically a high-risk, high-reward proposition. If losses because of defaults are less than $\$ 200$, then investors in the senior tranche receive $\$ 800$ at maturity. If losses because of defaults are more than $\$ 200$, then investors in the senior tranche will begin to experience losses to their principal.

In a typical CDO, the underlying pool of assets is split into four or five tranches, but the same waterfall method of apportioning losses in the underlying portfolio applies. The equity tranche absorbs the first losses; then, the losses flow down to the middle, or mezzanine, tranches. Finally, if the underlying portfolio suffers catastrophic losses, then investors in the senior and super-senior tranches will suffer losses to their invested principal. Investors in senior tranches seldom suffer any losses, and thus the yields on these tranches are often very close to the yields on highly rated corporate debt.

\section{The Impact of Correlation on CDO Prices}

Duffie and Gârleanu (2001) provided an excellent discussion of pricing CDOs. The two most important concepts in CDO pricing are tranching and default correlation. These two factors affect the junior and senior tranches differently. For example, suppose that the portfolio underlying a CDO is composed of just two bonds, each with a face value of $\$ 100$, and there is a 50 percent senior tranche and a 50 percent junior tranche. If we assume that there is no recovery in the event of default, then an investor in the senior tranche will lose principal only if both bonds default together. To illustrate the impact of default correlation on the prices of the two CDO tranches, we consider two extreme values for the correlation between default times of the bonds in the portfolio, -1 and 1 .

If default correlation is 1 , then both companies tend to default or not default together. The senior tranche is only affected if both companies default together, so default correlation of 1 is detrimental to senior tranche holders. Instead, if default correlation is -1 , then the companies rarely default together and it is more likely that only one company defaults. This situation benefits investors in the senior tranche, who lose principal only if both companies default together, but it hurts investors in the junior tranche, who need only one company to default in order to lose their principal.

We need to mention two final points. First, the level of correlation between bonds is seldom negative, yet the intuition of the previous example still holds: Low correlation is bad for investors in the equity tranche, and high correlation is bad for investors in the senior tranche. Moody's has developed a measure called the diversity score, which is used to estimate the correlation in the portfolio of debt instruments underlying a CDO. The diversity score is essentially the number of uncorrelated debt instruments that would have the same distributions of losses as the actual (correlated) portfolio underlying the CDO. Second, the impact of correlation on the middle, or mezzanine, tranches is ambiguous. Depending on how the specific CDO has been configured, the mezzanine 
tranches may not be affected by correlation at all, or they may be only slightly affected by correlation in either a beneficial or harmful way. This effect contrasts with the effect of correlation on the price of the first loss and senior tranche prices, where the correlation effect is systematic and unambiguous.

\section{Credit Indices}

Most CDO transactions to date have been customized transactions put together by investment banks. The bank decides which names to include in the underlying portfolio (usually more than 50 names), sources the credit exposure by purchasing bonds or by entering into CDS transactions, defines the tranching scheme, and then sells the tranches to various categories of investors. The equity tranche is often sold to hedge funds, and the senior tranche is often sold to pension funds and insurance companies.

The iTraxx indices have become popular standard credit benchmarks (see Duffie and Yurday 2004). It is possible to enter into a CDS transaction on the index, which gives the same credit risk exposure as owning this diversified portfolio outright. The iTraxx indices also have tradable, standardized CDO tranches. An investor can enter into a transaction to gain the same risk exposure as if he or she had actually invested in a CDO with an investment bank. The investor does not actually put up the investment funds that would be required for a traditional CDO tranche investment, so these standardized transactions are called synthetic tranches.

\section{Basket Default Swaps}

Basket default swaps are another class of credit derivatives that provide protection for defaults in an underlying basket of debt instruments. In a first-to-default swap, the buyer of protection pays a periodic fee in exchange for an insurance payment equal to the default loss on the first bond to default in the underlying portfolio. An investor in the equity tranche of a CDO on the same underlying portfolio also absorbs the first losses of the portfolio, so first-to-default protection can mitigate much of that risk.

An $n$ th-to-default swap is a variation on a first-to-default swap that works exactly as one would expect: The insurance payment is triggered when the $n$th company in the underlying portfolio defaults instead of when the first company defaults. As with CDO prices, rates on $n$ th-to-default swaps are sensitive to the default correlation between the bonds in the underlying portfolio. If the default correlation is high, then there is a greater chance that a large number of companies will default together. Therefore, if $n$ is large relative to the number of bonds in the underlying portfolio, then the $n$ th-to-default swap rate, or insurance payment, is also large when default correlation is high. Conversely, if default correlation is low, then it is more likely that there will be scenarios in which one (or more) of the companies in the portfolio defaults, but in each such scenario, the total companies that default are limited to a small number because of the low correlation. Because the frequency of scenarios in which at least one company defaults is high when default correlation is low, the first-to-default swap rate (and $n$ th-to-default swap rate for small $n$ ) will be relatively high. Intuitively, for small $n$, the $n$ th-to-default swap rate has a similar sensitivity to default correlation as the equity tranche of a CDO, whereas for large $n$, the $n$ th-to-default swap rate has a similar sensitivity to correlation as the senior tranche of a CDO. As with the mezzanine CDO tranches, the impact of correlation on the $n$ th-to-default swap rate is ambiguous for intermediate values of $n$. Hull and White (2004) provided an excellent discussion of the effect of correlation on CDO prices and $n$-to-default swap rates.

\section{Models of Correlated Default}

The credit risk models that we have reviewed up to this point address the default risk of a single company. As we have shown, prices of such hot credit derivatives as CDOs and $n$ th-to-default swaps are sensitive to the correlation in default risk between companies. Hence, much of the leading edge research in credit risk addresses models of correlated defaults.

There are two popular approaches to modeling correlated defaults. Duffie and Singleton (1999a) described models in which the default intensities of companies are correlated with one another. Alternatively, Li (2000) and Schöbucher and Schubert (2001) used copula functions (discussed in more detail later in this section) to overlay 
a correlation structure directly onto the default times of various companies. Each of these modeling choices has benefits and trade-offs. Although it is intuitively appealing to allow companies to have correlated default intensities, it can be challenging to implement these models. Copula functions do not have an easy economic interpretation, but it is easier to compute prices of many credit derivatives in these models.

We begin with an examination of correlated risk-neutral default intensities. In a model for the risk-neutral default probability of a single company, we allow its default intensity to move around randomly by supplying a volatility parameter. A model of the joint risk-neutral default intensities of many companies requires that we also supply the correlation between the risk-neutral default intensities of each pair of companies. For example, if there are 10 companies, then there are 45 different pairs of companies, each of which requires a correlation parameter. Duffie and Singleton (1999a) provided examples of how to model the risk-neutral default intensities of each company so that they are correlated through time.

Once we have a model for the correlated risk-neutral default intensities of the companies, we can jointly simulate the default times $\tau_{1}, \ldots, \tau_{10}$ of the 10 companies as though we have 10 separate models.

1. Simulate the 10 paths of correlated default intensities $\lambda_{1}(\cdot), \ldots, \lambda_{10}(\cdot)$ and 10 independent random numbers $U_{1}, \ldots, U_{10}$ that are uniformly distributed between 0 and 1 .

2. For each $j=1, \ldots, 10$,

- Set $\tau_{j}=T_{1}$ if

$$
0<U_{j} \leq 1-e^{-\Lambda_{j}\left(T_{1}\right) T_{1}} .
$$

- Set $\tau_{j}=T_{2}$ if

$$
1-e^{-\Lambda_{j}\left(T_{1}\right) T_{1}}<U_{j} \leq 1-e^{-\Lambda_{j}\left(T_{2}\right) T_{2}} .
$$

- In general, set $\tau_{j}=T_{m}$ ifl3

$$
1-e^{-\Lambda_{j}\left(T_{m-1}\right) T_{m-1}}<U_{j} \leq 1-e^{-\Lambda_{j}\left(T_{m}\right) T_{m}}
$$

The simulated default times $\tau_{j}$ are correlated across companies because the default intensities of the companies are correlated. For example, if the default intensities $\lambda_{1}(\cdot)$ and $\lambda_{2}(\cdot)$ are perfectly correlated, then the probability that default occurs in any period will be the same for both companies. However, it is important to realize that the default times $\tau_{1}$ and $\tau_{2}$ themselves are not perfectly correlated because the uniform random numbers $U_{1}$ and $U_{2}$ are drawn independently.

The algorithm for simulating correlated defaults using copula functions is the same as above except that:

1. The uniform random numbers $U_{1}, \ldots, U_{10}$ are correlated rather than independent. A copula function determines the correlation between the uniform random numbers.

2. The risk-neutral default intensities $\lambda_{1}(\cdot), \ldots, \lambda_{10}(\cdot)$ are deterministic, and therefore, they are not correlated. A copula is something that connects or ties things together. 14 In statistics, a copula function joins together individual, independent uniform random numbers into correlated uniform random numbers. In practical terms, copula functions are frequently used to generate correlated uniform random numbers. $\mathrm{Li}$ (2000) and Schöbucher and Schubert (2001) both used the Gaussian copula, which translates correlated Gaussian (or normal) random

13Again, recall that $\Lambda_{j}\left(T_{m}\right)\left(T_{m}\right)=\sum_{i=1}^{m} \lambda\left(T_{i}\right)\left(T_{i}-T_{i-1}\right)$. Also, note that the specific value of $T_{m}$ depends on $\Lambda_{j}(\cdot)$ and $U_{j} ;$ hence, it can differ for each $j=1, \ldots, 10$.

14In linguistics, "copula" is a word that connects the subject and predicate of a proposition. 
variables (which can be easily simulated) into correlated uniform random variables. 15 Das and Geng (2004) examined how well the Gaussian, Gumbel, Clayton, and Student's $t$ copulas fit the joint default process of companies and found that the Clayton copula fits best.

In the copula modeling approach, the default times $\tau_{1}, \ldots, \tau_{10}$ are correlated because the uniform random numbers $U_{1}, \ldots, U_{10}$ are correlated. The reason for this is that, all else equal, if $U_{j}$ is small for the $j$ th company, then that company's default time $\tau_{j}$ also tends to be small (and vice versa). Thus, if $U_{1}$ and $U_{2}$ are positively correlated, then $U_{1}$ tends to be small when $U_{2}$ is small (and vice versa); $\tau_{1}$ and $\tau_{2}$ are also positively correlated because $\tau_{1}$ tends to be small when $\tau_{2}$ is small (and vice versa).

To recap, the two most popular methods for modeling correlated defaults are as follows:

1. In one method, the risk-neutral default intensities of the companies are correlated with one another, but the uniform random numbers are not correlated with each other. Duffie and Singleton (1999a) provided examples of this modeling approach.

2. In another method, a copula function is used to generate correlated uniform random numbers but deterministic default intensities are used. $\mathrm{Li}$ (2000) and Schöbucher and Schubert (2001) provided examples of this modeling approach.

Both of these modeling approaches require as input a correlation value between each company. In theory, this correlation could differ for each pair of companies; however, practitioners typically use the same correlation for all pairs of companies. There is also the question of which correlation to use. For models of correlated default intensities, there is a direct relationship between the correlation in credit spreads between companies and the correlation between their risk-neutral default intensities. Hence, one can estimate the historical correlations between credit spreads for each pair of companies and use these estimates as the correlation between their default intensities. There is no such direct relationship for models that use the copula approach, and practitioners instead often use the correlations estimated from the asset returns of the companies.

The prices of credit derivatives are also frequently used to infer the implied correlation input. That is, models of correlated default are calibrated to match the market prices of common credit derivatives. For example, the market prices of the synthetic tranches on the iTraxx indices are completely transparent, and traders can use the price of each tranche to infer the risk-neutral default correlation between the issuers in the underlying portfolio (just as options traders use market prices to infer option-implied volatilities). The implied default correlation can vary dramatically depending on which tranche price is used to infer the correlation. This difference in implied default correlation is not consistent with the model because the underlying portfolio of companies is the same for each tranche and, therefore, the correlation between the companies should not change. This "implied correlation smile" problem is a major subject of current research efforts.

It can be computationally intensive to price credit derivatives that depend on a large number of correlated defaults, and much has been written on efficiently computing prices. Chen and Glasserman (2006) provided a method for valuing default swaps using Monte Carlo simulations and a technique called importance sampling to speed up the necessary computations. Much of the literature on computing prices of credit derivatives uses factor copulas that almost provide closed-form solution for prices. A factor copula can be used to generate 10 correlated normal random numbers $X_{1}, \ldots, X_{10}$ as follows:

1. Generate a normal random number $Z$ and 10 independent normal random numbers $\varepsilon_{1}, \ldots, \varepsilon_{10}$.

2. Set $X_{i}=\rho \times X+\sqrt{1-\rho^{2}} \varepsilon_{i}$. The correlation between $X_{i}$ and $X_{j}$ (for $\left.i \neq j\right)$ is $\rho$.

The Gaussian copula is then used to translate the correlated normal random variables $X_{1}, \ldots, X_{10}$ into correlated uniform random variables $U_{1}, \ldots, U_{10}$. This approach to generating correlated normal random numbers is particularly useful because, conditional on the common value of $X$, the default times of the companies are independent of each other and, therefore, the prices of many credit derivatives can be computed in closed form

15 More formally, for correlated normal random variables $X_{1}, \ldots, X_{10}$, the Gaussian copula generates correlated uniform random numbers $U_{1}, \ldots, U_{10}$ by setting $U_{i}=N\left(X_{i}\right)$, where $N(\cdot)$ is the cumulative distribution function of a standard normal variable. 
(again, conditional on the value of $X$ ). Two popular approaches to iterating over the range of values of $X$ to compute the unconditional price of a credit derivative are transform analysis, used by Laurent and Gregory (2005), and the bucketing approach, used by Andersen and Sidenius (2005) and Hull and White (2004).

Collin-Dufresne, Goldstein, and Helwege (2003) documented that marketwide credit spreads increase when companies default, and Das, Duffie, Kapadia, and Saita (forthcoming 2007) find that defaults are more clustered than would be implied by the standard model of correlated default intensities. Collin-Dufresne et al. (2003) and Giesecke (2004) provided general models of correlated default intensities in which one company's default can affect the probability of default and credit spread of other companies in the economy.

\section{Pricing a CDO by Monte Carlo Analysis}

Monte Carlo analysis is a popular method for pricing credit derivatives, such as CDOs. To illustrate this approach, suppose that the portfolio underlying a CDO contains 10 zero-coupon bonds that each matures in three years. If an issuer defaults before maturity, then the bond pays $\$ 50$ in Year 3; otherwise, it pays the full face value of $\$ 100$. The CDO has a junior tranche that absorbs the first 20 percent of portfolio losses and a senior tranche that absorbs any losses greater than 20 percent. The following algorithm can be used to compute the price of the junior and senior tranches using Monte Carlo analysis:

1. Simulate 10 correlated default times $\tau_{1}, \ldots, \tau_{10}$ using either the copula approach or correlated risk-neutral default intensities. 16

2. Compute the payoff to each tranche of the CDO. If there are no default times less than three years, then the junior tranche receives $\$ 200$ and the senior tranche receives $\$ 800$. If there are four defaults before Year 3 , then the junior tranche receives $\$ 0$ and the senior tranche receives $\$ 800$. If there are five defaults before Year 3 , then the junior tranche receives $\$ 0$ and the senior tranche receives $\$ 750$. In general, if there are $n$ defaults before Year 3, then the junior tranche receives $\$ 200-\min (n, 4) \times \$ 50$ and the senior tranche receives $\$ 800-\max (n-4,0) \times \$ 50$.

3. Repeat Steps 1 and 2 a large number of times (e.g., 50,000) and compute the average payoff to the junior and senior tranches. As the number of simulations gets large, the average payoff becomes a close approximation to the risk-neutral expected payoff.

4. Discount the risk-neutral average payoffs (computed in Step 3) by the three-year risk-free rate to obtain the prices of the junior and senior tranches.

A supplemental spreadsheet (available online) that accompanies this literature review demonstrates how to use the copula approach and correlated risk-neutral default intensities to price credit derivatives, such as CDOs.

\section{Summary}

In this literature review, we discussed credit risk modeling and the pricing of such credit derivatives as CDS and CDOs. There are two broad approaches to modeling the credit risk exposure of a single company:

- In structural models, the company's assets are assumed to vary randomly over time. Default occurs when (if) the value of the company's assets dips below some level (e.g., the amount of debt the company has outstanding).

- In reduced-form models, the probability of default is modeled directly using the company's hazard rate or default intensity. A company's risk-neutral default intensity can vary randomly over time and is closely related to the credit spread that the company pays to borrow money.

Reduced-form pricing models are predominantly used in the industry for pricing derivatives. In a reducedform pricing model, the company's risk-neutral default intensity is used to model the company's probability of default. The company's risk-neutral default intensity is usually higher than its actual default intensity. This difference reflects investors' risk aversion to holding the company's debt in the event that it defaults. We provided a simple algorithm for simulating the default behavior of a single company based on either its actual or risk-neutral default intensity.

\footnotetext{
16 One could also use a combination of these two approaches.
} 
We reviewed credit risk models and credit derivatives based on a portfolio of companies. We illustrated the effect of default correlation on CDO prices and basket default swap rates. We discussed the two popular approaches to modeling correlated default risk:

- The risk-neutral default intensities are correlated with one another.

- A copula function is used to overlay a correlation structure directly onto the default times.

Copula functions are frequently used in practice because they allow prices of many credit derivatives to be easily computed (although these models do have some inconsistencies, such as the "implied correlation problem"). We briefly reviewed the factor copula models that have been used to speed up the pricing computations. Finally, we illustrated how to use these two approaches to simulate correlated default times and price a CDO by Monte Carlo analysis.

Jeremy Graveline would like to acknowledge Darrell Duffie and Ken Singleton. Michael Kokalari would like to acknowledge the assistance of Matthew Leduc, Xiaowei Ding, and Xiaolei Yao on portions of this article.

This publication qualifies for 1 CE credit. 


\section{References}

Acharya, Viral V., Sreedhar T. Bharath, and Anand Srinivasan. Forthcoming 2006. "Does Industry-Wide Distress Affect Defaulted Firms? Evidence from Creditor Recoveries.” Journal of Financial Economics.

Recovery rates decrease during economic downturns as well as when the industry is in distress and other nondefaulted companies in the industry are illiquid.

Altman, Edward I. 1968. "Financial Ratios, Discriminant Analysis and the Prediction of Corporate Bankruptcy." Journal of Finance, vol. 23, no. 4 (September):589-609.

This article presents one of the first quantitative models for predicting bankruptcy. Five key financial ratios are used to compute a company's $Z$-score, which is, in turn, used to predict default. The most significant financial ratio for predicting default is earnings before income and taxes divided by total assets.

Altman, Edward I., Brooks Brady, Andrea Resti, and Andrea Sironi. 2005. "The Link between Default and Recovery Rates: Theory, Empirical Evidence and Implications." Journal of Business, vol. 78, no. 6 (November):2203-2228.

This empirical article finds that recovery rates are a function of supply and demand for defaulted securities: Recovery rates are low when aggregate defaults are high, and vice versa.

Altman, Edward I. 2006. "Estimating Default Probabilities of Corporate Bonds over Various Investment Horizons.” CFA Institute Conference Proceedings Quarterly, vol. 23, no. 1 (March):65-71. [added April 2008]

"In advance of forthcoming regulatory changes, commercial banks have developed sophisticated internal credit models that consider the risk of their counterparties. Even though these models suffer from high Type II errors - false forecasts of default - they tend to be quite accurate in bankruptcy prediction. Although external credit rating agencies excel at assessing the initial rating of a corporate bond, they are slow to change their ratings in light of new information. The flexibility and ease of use of a well-known internal credit model, first developed in the 1960s, and the extensive default histories of the external rating agencies can be combined to predict the probability of default over investment horizons stretching from 1 year to 10 years." (p. 65)

2006. "Credit Risk and the Link between Default and Recovery Rates." CFA Institute Conference Proceedings Quarterly, vol. 23, no. 3 (September):34-43. [added April 2008]

"The U.S. high-yield bond market has grown dramatically in the past three decades, reaching more than $\$ 1$ trillion in outstanding debt as of mid-year 2006. But little rigorous analysis has been done on what happens to the recovery rate over the credit cycle. Most models assume a fixed recovery rate, but a recent model that was tested using more than 1,000 defaulted bonds shows an inverse relationship between the probability of default and the recovery rate. Based on this model, several industries may be quite vulnerable to a high risk of default in the current environment." (p. 34)

Andersen, Leif, and Jakob Sidenius. 2005. "Extensions to the Gaussian Copula: Random Recovery and Random Factor Loadings." Journal of Credit Risk, vol. 1, no. 1 (Winter):29-70.

This article presents a reduced-form pricing model with recovery rates that are correlated with aggregate defaults, as in Altman et al. (2005) and Acharya et al. (forthcoming 2006). Pricing computations use the bucketing approach. 
Arora, Navneet, Jeffrey R. Bohn, and Fanlin Zhu. 2005. "Reduced Form vs. Structural Models of Credit Risk: A Case Study of Three Models.” Journal of Investment Management, vol. 3, no. 4 (Winter):43-67. [added April 2008]

"This paper discusses and empirically tests the relative merits of three models of credit default risk: two structural models (Merton and Vasicek-Kealhofer [VK]) and one reduced-form model (Hull-White [HW]). The authors find that the VK and HW models predict defaults reasonably well and both clearly outperform the Merton model. Using credit default swap (CDS) data from 2000 to 2004, the authors also show that the VK model generally outperforms the HW and Merton models in its ability to predict the level and cross variation in CDS spreads." [Bruce D. Phelps, CFA, CFA Digest, May 2006]

Avramov, Doron, Gergana Jostova, and Alexander Philipov. 2007. "Understanding Changes in Corporate Credit Spreads." Financial Analysts Journal, vol. 63, no. 2 (March/April):90-105. [added April 2008]

"New evidence is reported on the empirical success of structural models in explaining changes in corporate credit risk. A parsimonious set of common factors and company-level fundamentals, inspired by structural models, was found to explain more than 54 percent (67 percent) of the variation in credit-spread changes for medium-grade (low-grade) bonds. No dominant latent factor was present in the unexplained variation. Although this set of factors had lower explanatory power among highgrade bonds, it did capture most of the systematic variation in credit-spread changes in that category. It also subsumed the explanatory power of the Fama and French factors among all grade classes." (p. 90)

Avramov, Doron, Tarun Chordia, Gergana Jostova, and Alexander Philipov. 2007. "Momentum and Credit Rating." Journal of Finance, vol. 62, no. 5 (October):2503-2520. [added April 2008]

"The capital asset pricing model anomaly-momentum profits from buying past winners and selling past losers-is not explained by the Fama and French three-factor model. This article provides a new explanation of momentum strategy profitability. Momentum profits are strongly influenced by credit quality. The influence is limited to a small sample of high-credit-risk companies that account for about 4 percent of market capitalization, and the results are robust." [Charles F. Peake, CFA, CFA Digest, February 2008]

Bedendo, Mascia, Lara Cathcart, and Lina El-Jahel. 2007. "The Slope of the Term Structure of Credit Spreads: An Empirical Investigation." Journal of Financial Research, vol. 30, no. 2 (Summer):237-257. [added April 2008]

"Credit spread slopes of corporate bonds reveal changes in the direction of future short-term credit spreads and thus provide important information for the trading and risk management of multi-credit, multi-maturity bond portfolios. Furthermore, interest rate, market, and idiosyncratic equity variables influence changes in the credit spread slope, affecting spreads at the long and short ends of the yield curve in significantly different ways." [Kathryn Dixon Jost, CFA, CFA Digest, November 2007]

Berndt, Antje, Rohan Douglas, Darrell Duffie, Mark Ferguson, and David Schranz. 2005. "Measuring Default Risk Premia from Default Swap Rates and EDFs.” Bank for International Settlements Working Paper No. 173.

This empirical study uses default swap rates and default probability from Moody's KMV EDFs to examine the price of default risk. The authors find dramatic variation in risk premiums in the broadcasting and entertainment, health care, and oil and gas sectors over the 2000-04 sample period.

Black, Fischer, and Myron Scholes. 1973. "The Pricing of Options and Corporate Liabilities." Journal of Political Economy, vol. 81, no. 3 (May/June):637-654.

This seminal paper develops the famous Black-Scholes option pricing formula and illustrates how it can be used to price corporate liabilities, which can be viewed as put options on the assets of the company. 
Cardinale, Mirko. 2007. "Corporate Pension Funding and Credit Spreads.” Financial Analysts Journal, vol. 63, no. 5 (September/October):82-101. [added April 2008]

"This study empirically tested whether pension information derived from accounting disclosures is priced in corporate bond spreads. The model was tested on corporate bond data of U.S. companies for the 2001-04 period. Unfunded pension liabilities are incorporated in credit spreads, and the sensitivity of market spreads to deficits is greater than the sensitivity to ordinary long-term debt. This relationship is not, however, a linear monotonic function, and the sensitivity of bond spreads to deficits is substantially higher for high-yield than for investment-grade bonds. Moreover, the bond market prices residual risk even in funded obligations and gives lower weighting to off-balance-sheet liabilities." (p. 82)

Chen, Long, David A. Lesmond, and Jason Wei. 2007. "Corporate Yield Spreads and Bond Liquidity." Journal of Finance, vol. 62, no. 1 (February):119-149. [added April 2008]

"The authors study the relationship between corporate bond liquidity and yield spreads by using a large, comprehensive sample of corporate bonds and three measures of liquidity. The authors find that liquidity is a prime determiner of yield spreads, explaining up to half of the cross-sectional variation in spread levels and up to two times the cross-sectional variation in spread changes that is explained by the effects of credit rating alone. These findings support the concern in the literature of default risk that neither yield-spread levels nor changes of spreads can be fully explained by default risk determinants." [Edgar J. Sullivan, CFA, CFA Digest, August 2007]

Chen, Zhiyong, and Paul Glasserman. 2006. "Fast Pricing of Basket Default Swaps.” Working paper (March). An efficient method for computing basket default swap rates using Monte Carlo methods is presented. The paper also discusses factor copulas used for modeling correlated defaults.

Collin-Dufresne, Pierre, Robert S. Goldstein, and J. Spencer Martin. 2001. "The Determinants of Credit Spread Changes." Journal of Finance, vol. 56, no. 6 (December):2177-2207.

Variation in leverage and volatility (important variables in structural pricing models) account for only a small portion of credit spreads. The authors find that a single (unexplained) common factor drives the credit spreads of the companies in their sample.

Collin-Dufresne, Pierre, Robert S. Goldstein, and Jean Helwege. 2003. "Is Credit Event Risk Priced? Modeling Contagion via the Updating of Beliefs." Working paper (10 December).

Marketwide credit spreads increase when large companies default. The paper develops a theoretical reduced-form pricing model in which a default by one company can trigger an increase in the riskneutral default intensities of other companies.

Crosbie, Peter, and Je Bohn. 2003. “Modeling Default Risk.” Moody's KMV (18 December).

This paper describes Moody's KMV method for predicting default using a company's distance to default and EDF.

Das, Sanjiv R., Darrell Duffie, Nikunj Kapadia, and Leandro Saita. 2007. "Common Failings: How Corporate Defaults Are Correlated.” Journal of Finance, vol. 62, no. 1 (February):93-117.

This empirical paper finds that defaults are more clustered than would be implied by the standard model of correlated default intensities. Richer models, such as those by Collin-Dufresne et al. (2003) and Giesecke (2004), can better capture this clustering.

Das, Sanjiv R., and Garg Geng. 2004. "Correlated Default Processes: A Criterion-Based Copula Approach.” Journal of Investment Management, vol. 2, no. 2 (Second Quarter):44-70.

In this empirical study that examines how well the Gaussian, Gumbel, Clayton, and Student's $t$ copulas fit the joint default process of companies, the authors find that the Clayton copula does the best job of matching the default correlation of issuers. 
Davydenko, Sergei A. 2005. "When Do Firms Default? A Study of the Default Boundary." Working paper, University of Toronto (1 February).

This empirical paper finds that temporary liquidity shortages can trigger default when outside financing is not available. Additionally, the study finds that low asset levels increase the probability of default.

Dor, Arik Ben, Lev Dynkin, Jay Hyman, Patrick Houweling, Erik van Leeuwen, and Olaf Penninga. 2007. "DTS ${ }^{\text {sm }}$ (Duration Times Spread)." Journal of Portfolio Management, vol. 33, no. 2 (Winter):77-100. [added April 2008]

"The authors study the behavior of spread changes and recommend a new approach, Duration Times Spread (DTS), to measuring risk in credit portfolios, which measures the sensitivity to a relative change in spread. After analyzing the spread behavior of corporate bonds, the authors examine whether DTS or spread duration is better for measuring the excess return volatility of credit securities. The authors conclude that the DTS methodology accurately represents the impact of spread changes on excess return." [Ahmed Olayinka Sule, CFA, CFA Digest, August 2007]

Driessen, Joost. 2005. "Is Default Event Risk Priced in Corporate Bonds?" Review of Financial Studies, vol. 18, no. 1 (April):165-195.

Expected corporate bond returns are decomposed into default, liquidity, and tax components. This empirical study is one of the first to examine the ratio of risk-neutral to actual default intensities.

Duffee, Gregory R. 1999. "Estimating the Price of Default Risk.” Review of Financial Studies, vol. 12, no. 1 (Spring):197-226.

This empirical article estimates a reduced-form pricing model for corporate bonds and finds that it is reasonably successful at fitting yields.

Duffie, Darrell. 1999. “Credit Swap Valuation.” Financial Analysts Journal, vol. 55, no. 1 (January/February):73-87.

The author reviews the contract details and pricing of credit swaps.

Duffie, Darrell, and Nicolae Gârleanu. 2001. "Risk and Valuation of Collateralized Debt Obligations.” Financial Analysts Journal, vol. 57, no. 1 (January/February):41-59.

This article examines the effects of correlation and tranching on the pricing of CDOs.

Duffie, Darrell, and Ming Huang. 1996. "Swap Rates and Credit Quality.” Journal of Finance, vol. 51, no. 3 (July):921-949.

This theoretical article presents a model for valuing derivatives in which both counterparties in the contract can default.

Duffie, Darrell, and Kenneth Singleton. 1999a. "Simulating Correlated Defaults." Working paper, Stanford University (21 May).

The authors describe approaches to modeling and simulating correlated default times.

—. 1999b. "Modeling Term Structures of Defaultable Bonds." Review of Financial Studies, vol. 12, no. 4 (Special):687-720.

The authors develop a popular reduced-form model for pricing defaultable bonds. The model assumes that in the event of default, investors receive a fraction (or, equivalently, lose a fixed fraction) of what the claim was worth immediately prior to default. This tractable assumption is referred to as recovery of market value. 
Duffie, Darrell, and Erin C. Yurday. 2004. “Structured Credit Index Products and Default Correlation.” Stanford Graduate School of Business Case F-269.

This case study examines the prices of tranches on the iTraxx indices.

Duffie, Darrell, Lasse Heje Pedersen, and Kenneth J. Singleton. 2003. "Modeling Sovereign Yield Spreads: A Case Study of Russian Debt.” Journal of Finance, vol. 58, no. 1 (February):119-159.

This article extends the reduced-form pricing model in Duffie and Singleton (1999b) to the pricing of sovereign debt. The model is estimated using Russian dollar-denominated bonds.

Duffie, Darrell, Leandro Saita, and Ke Wang. Forthcoming. "Multi-Period Corporate Default Prediction with Stochastic Covariates." Journal of Financial Economics.

This empirical study estimates the conditional probabilities of default over multiple future periods.

The hazard rate model depends on the dynamics of company-specific and macroeconomic variables.

The most influential variable for predicting default is a company's distance to default.

Elton, Edwin J., Martin J. Gruber, Deepak Agrawal, and Christopher Mann. 2001. "Explaining the Rate Spread on Corporate Bonds." Journal of Finance, vol. 56, no. 1 (February):247-277.

The authors document evidence of a risk premium on corporate bonds over and above expected losses because of default.

Fabozzi, Frank J. 2007. Fixed Income Analysis, Second Edition. Charlottesville, VA: CFA Institute Investment Series. [added April 2008]

"This fully revised edition covers the fixed-income marketplace, the risks associated with investing in fixed-income securities, and the fundamentals of valuation and interest rate risk. This book also examines the valuation of fixed-income securities with embedded options, the features of structured products, and the principles of credit analysis. Rounding out the discussion, Fixed Income Analysis, Second Edition demonstrates how to construct a portfolio that is in line with your investment objectives.” (p. 1)

Giesecke, Kay. 2004. "Correlated Default with Incomplete Information.” Journal of Banking E Finance, vol. 28, no. 7 (July):1521-1545.

The author develops a structural model of multicompany default. Default times are correlated because when one company defaults, investors learn more about the default boundaries of other related companies in the economy.

Hull, John, and Alan White. 2000. "Valuing Credit Default Swaps I: No Counterparty Default Risk.” Journal of Derivatives, vol. 8, no. 1 (Fall):29-40.

This article is the first of a two-part study on valuing CDS.

—. 2001. "Valuing Credit Default Swaps II: Modeling Default Correlations." Journal of Derivatives, vol. 8, no. 3 (Spring):12-22.

The second part of a two-part study, this article focuses on modeling default correlation and addresses the pricing of basket CDS and CDS with counterparty risk.

- 2004. "Valuation of a CDO and $n$th to Default CDS without Monte Carlo Simulation." Journal of Derivatives, vol. 12 , no. 2 (Winter):8-23.

This article values CDOs and $n$ th-to-default swaps using a factor copula model and a variation of the bucketing method presented in Andersen and Sidenius (2005). 
Jarrow, Robert A., David Lando, and Stuart M. Turnbull. 1997. "A Markov Model for the Term Structure of Credit Risk Spreads.” Review of Financial Studies, vol. 10, no. 2 (Summer):481-523.

The authors develop a popular reduced-form pricing model in which a company's default intensity (hazard rate) depends on its credit rating. This model is especially useful for valuing credit derivatives with payoffs that depend on a company's credit rating.

Jorion, Philippe, and Gaiyan Zhang. 2007. "Good and Bad Credit Contagion: Evidence from Credit Default Swaps.” Journal of Financial Economics, vol. 84, no. 3 (June):860-883. [added April 2008]

"The authors examine the correlation of credit default swap spreads and equity prices for companies in a common industry during an extreme credit event. Findings indicate that contagion effects contribute to positive correlations around Chapter 11 filings and other large, unanticipated credit events. Negative correlations and competitive effects prevail amid Chapter 7 events. The findings offer insight toward constructing better diversified, credit-sensitive portfolios that are more resilient to extreme events." [Michael Kobal, CFA, CFA Digest, November 2007]

Kealhofer, Stephen. 2003. “Quantifying Credit Risk I: Default Prediction.” Financial Analysts Journal, vol. 59, no. 1 (January/February):30-44.

The author reviews the KMV approach to predicting default using a company's distance to default and its EDF.

Lando, David. 1998. "On Cox Processes and Credit-Risky Securities." Review of Derivatives Research, vol. 2, nos. 2-3:99-120.

This article develops the basis for reduced-form pricing models and generalizes the model in Jarrow et al. (1997)

Laurent, Jean-Paul, and Jon Gregory. 2005. “Basket Default Swaps, CDOs and Factor Copulas.” Journal of Risk, vol. 7 , no. 4 (Summer):103-122.

This theoretical article uses factor copulas and transform analysis to price basket default swaps and CDO tranches.

Leland, Hayne E. 1994. “Corporate Debt Value, Bond Covenants, and Optimal Capital Structure.” Journal of Finance, vol. 49, no. 4 (September):1213-1252.

The author extends the standard structural pricing model of Black and Scholes (1973) and Merton (1974) and allows companies to optimally choose the time they default.

Li, David X. 2000. “On Default Correlation: A Copula Function Approach.” Journal of Fixed Income, vol. 9, no. 4 (March):43-54.

This seminal article uses copulas to model correlated defaults. This study was the topic of a front page article by Mark Whitehouse in the Wall Street Journal entitled "How a Formula Ignited a Market That Burned Investors" (12 September 2005).

Lin, Mingyan, and Jean-Christophe Curtillet. 2007. "Another Look at the Relation between Credit Spreads and Interest Rates." Journal of Fixed Income, vol. 17, no. 1 (Summer):59-71. [added April 2008]

"The authors find that different risk components in the credit spreads may have different relationships with the interest rate. They present a statistical model that captures the short-term dynamics of credit spreads. In particular, they find that whether credit spreads widen when the Fed raises its target rate depends on the lagged response of the yield curve. On a long-term basis, credit spreads widen in response to crises, significant financial events, and recession but are not determined by interest rates." [Deborah Kidd, CFA, CFA Digest, February 2008] 
Longstaff, Francis A., Sanjay Mithal, and Eric Neis. 2005. "Corporate Yield Spreads: Default Risk or Liquidity? New Evidence from the Credit Default Swap Market.” Journal of Finance, vol. 60, no. 5 (October):2213-2253. [added April 2008]

"The authors use bond prices and credit default swap premiums to determine the composition of corporate yield spreads. Although default risk accounts for most of the spread, there is also a significant time-varying nondefault component directly related to liquidity effects. The results extend earlier research that considers the market price of credit risk to be higher than implied by select structural models." [Christopher J. Sullivan, CFA, CFA Digest, February 2006]

Merton, Robert C. 1974. "On the Pricing of Corporate Debt: The Risk Structure of Interest Rates.” Journal of Finance, vol. 29, no. 2 (May):449-470.

This seminal paper developed the structural model for pricing corporate debt subject to default risk.

O'Kane, Dominic, and Stuart M. Turnbull. 2003. "Valuation of Credit Default Swaps." Lehman Brothers Quantitative Credit Research Quarterly, vol. 2003-Q1-Q2 (April).

This article is a practitioner-oriented survey on the pricing of CDS.

Papageorgiou, Nicolas, and Frank S. Skinner. 2006. “Credit Spreads and the Zero-Coupon Treasury Spot Curve." Journal of Financial Research, vol. 29, no. 3 (Fall):421-439. [added April 2008]

"An investigation into the relationship between credit spreads and both the level and slope of the Treasury yield curve suggests that they are negatively correlated, so that an increase in either the level or slope of the curve accompanies a decrease in credit spreads. This relationship is found to be relatively stable over time, and although the responsiveness of credit spreads to interest rates does increase with maturity, it does not vary according to credit quality." [Gerard Breen, CFA, CFA Digest, February 2007]

Schaefer, Stephen M., and Ilya A. Strebulaev. 2004. "Structural Models of Credit Risk Are Useful: Evidence from Hedge Ratios on Corporate Bonds.” Working paper (May).

This empirical paper shows that structural pricing models are useful for hedging corporate debt with equity.

Schöbucher, Philipp J., and Dirk Schubert. 2001. "Copula-Dependent Default Risk in Intensity Models." Working paper (December).

This seminal paper uses copulas to model correlated defaults. The paper uses the Gaussian, Clayton, and Gumbel copulas.

Shumway, Tyler. 2001. "Forecasting Bankruptcy More Accurately: A Simple Hazard Model." Journal of Business, vol. 74, no. 1 (January):101-124.

The author estimates a hazard rate model for predicting default and finds that market size and past stock returns help to predict default.

Spentzos, George. 2006. "Using Credit Derivatives to Enhance Return and Manage Risk." CFA Institute Conference Proceedings Quarterly, vol. 23, no. 3 (September):44-51. [added April 2008]

"The credit derivatives market is growing rapidly in size as well as importance. Credit default swaps, the building blocks in the market, have several advantages over corporate bonds and asset swaps—not least of which is the ability to disaggregate the interest rate component from the credit component. The predominant strategies that hedge funds and other managers use to optimize credit portfolios are basis trades, curve trades, index trades, options trades, capital structure trades, and correlation trades.” (p. 44) 
Wallison, Peter J. 2009. "Everything You Wanted to Know about Credit Default Swaps: But Were Never Told." Journal of Structured Finance, vol. 15, no. 2 (Summer):20-30. [added February 2010]

"Recent articles have characterized credit default swaps (CDS) as sources of risk for institutions that use them, potential contributors to systemic risk, and the underlying reason that such companies as AIG had to be bailed out. The author asserts that these assessments are incorrect and reflect a misunderstanding of how CDS work and how they contribute to risk management. To counteract the misguided assertions and explain the positive benefits of CDS, he presents an assessment of the current situation and then recommends what should and should not be done to remedy the financial landscape." [Frank T. Magiera, CFA, CFA Digest, February 2010] 